\title{
Model Construction of Psychological Health Education in Universities from the Perspective of Synergetic Theory
}

\author{
Jian-Hong LU \\ Institute of Life Sciences and Food Engineering, Shaanxi Xueqian Normal University, Shaanxi, China; \\ azurelu2008@163.com
}

\begin{abstract}
Synergetic was a new developing subject, which was based on the multi-disciplinary knowledge by the Professor Herman'Haken of the University of Stuttgart in Germany's federal in 1970s. This essay is mainly to explore a new model of psychological health education in Colleges and universities for enhancing their effectiveness of psychological health education in the perspective of the slaving principles, synergetic effects and self-organization function in the synergetic theory.
\end{abstract}

Keywords-psychological health education, synergetic theory, strategy research

\section{INTRODUCTION: SYNERGETIC PRINCIPLE AND ITS BASIC POINT OF VIEW}

Synergetic was a new developing subject, which was based on the multi-disciplinary knowledge by the Professor Herman. Haken of the University of Stuttgart in Germany's federal in 1970s. The main research principle of synergetic is the spontaneous, spatial, temporal and functional nonlinear synergy of the open system with the exchange of substance from the outside. The research foundation of synergetic theory is the system information theory, control theory and catastrophe theory, and draws abundant achievements from dissipative theory to describe the transition rule of system from disorder to order[1]. The basic views of synergetic are as follows:

The slaving principle adheres to the principles that the slow variable obeys the fast variable, and the order parameter decides the behavior of the subsystem[2]. Its essence lies in the "configuration decision of slow growth and the impact of the rapid attenuation of configuration", when organization system approaches a critical point of instability, the emergent structure and dynamic characteristics are usually determined by the order parameter, and the other variables in the system are controlled and regulated by the order parameter.

Synergy effect refers to the overall utility of the effects of subsystems in an open system. In the open system, the interactions between the external forces make the material aggregation reach a critical point, and the subsystems within the system will produce synergy[3]. The coordination of this particular stage makes the system change at a specific critical point and produce synergistic reaction. The system structure changes from disorder to order and produces a stable material structure.
The principle of self-organization is the relative concept with hetero-organization principle. Organizational capabilities and organizational directives come from the hetero-organization outside of the system. When the system is in the absence of external forces, its subsystems can still follow certain rules to form a certain functional domain structure. Under the condition of effective input material flow, energy flow and information flow, a new stable structure in space and time will be formed based on the synergistic effect among subsystems.

\section{THE LIMITATIONS OF THE PSYCHOLOGICAL HEALTH EDUCATION MODEL}

The current psychological counseling in Colleges and universities can be divided into three modes: obstacle psychological counseling, adaptive psychological counseling and developing psychological counseling. Obstacle psychological counseling is to provide psychological assistance, support, interventions and treatment for consulting objects with various psychological problems to eliminate the psychological barriers and prompt their mental to the healthy direction. Adaptive psychological counseling is the psychological counseling to the people who are in the changing environment or suffer adverse stimulation of daily life. They also have the susceptible personality and the poor adaptability which lead to adaptive psychological adaptability problems or obstacles[4]. Adaptive psychological counseling is to facilitate the objects adapt to the learning and working lives faster and better. The developing psychological counseling is based on the general rules and characteristics of individual and their physical and mental development to help them complete the task of each psychological development successfully, help them solve the psychological contradiction, properly, and understand the society and themselves in order to improve their personalities. 


\section{THE MODEL CONSTRUCTION APPROACHES OF PSYCHOLOGICAL HEALTH EDUCATION IN UNIVERSITIES FROME THE PERSPECTIVE OF SYNERGETIC THEORY}

The leading role of collaborative model construction is to integrate the psychological health education resources in Colleges and universities effectively to come into a psychological health education system with great overall effectiveness from disorder to order. Meanwhile, model construction of psychological health education in Universities needs the collaboration of social subsystems with guidance mode, work force, education strength, the ways of implementation of collaborative effort.

\section{A. Synergy of Counseling Model to Maximize the Effectiveness of Mental Health Education}

There are three basic models of College Students' psychological counseling for adaptability, development and obstacles, and each model has its own limitations, we need to make the necessary coordination and integration. Meanwhile, this kind of integration is not a simple superposition but the orderly integration together. The ultimate goal of education is to prompt the development of all-round people. However, $17 \%$ of the college students have psychological problems. That is to say, the majority of College Students' psychological development is normal[5]. Developmental guidance is the most suitable mode of higher education and the development of College Students' physical and mental development. Therefore, in the process of psychological health education in Colleges and universities, we should focus on the mode of developing psychological counseling, aided by the counseling of adaptability to complementary advantages, to maximize the effectiveness of mental health education.

\section{B. Synergy of Team-work to Build High-quality Mental Health Education Team}

Psychological educators, moral educators and medical workers are the main forces to support the psychological health education team in china. These three psychological education teams not only have their respective characteristics, but also have their own shortcomings. Therefore, only by making full use of their advantages to work together and integrate learning, can we jointly build a high-quality and professional mental health education team. We should strive to strengthen theoretical learning, practical operation and scientific research. In the process of psychological health education in Colleges and universities, scientific research should be carried out to discover, analyze and solve problems, and participate in various kinds of academic conferences and exchange of experience, so as to broaden horizons and enhance scientific research ability. Of course, college mental health education team in addition to the three power, still need to school all kinds of community strength, management personnel and professional personnel of various disciplines of education work closely together, truly is involved.

\section{Synergy of Educational forCes to Deconstruct the Efficient Psychological Health Education Mode}

The psychological health education in colleges and universities is a full participation activity with professional psychological counseling teachers and psychological educators as the core. At the same time, outside of the colleges and universities, it also needs effective integration of society and family, and coordinated the construction of an overall education network with the University as the main body and the cooperation between the family and the society[6]. The advantages of college mental health education lie in three aspects. The first is that the colleges and universities possess the strict organizational leadership, good educational environment, professional psychological education groups and the specific educated groups which provide the good basis for mental psychological education work. The second is the psychological health education in Colleges and universities is systematic and organized. The third is the psychological health education in Colleges and universities usually arrange and carry out propaganda and popularization activities according to the characteristics of physical and mental development of college students and the law of education and teaching. The fourth is the psychological health education in the general colleges and universities is facing all the university students, with the developing responsibility of each independent student individual. Therefore, the psychological health education is an arduous and systematic project. Colleges and universities are the main positions for psychological education. Meanwhile, they should work together with the families and society to promote the healthy growth of students.

\section{Synergy of Implementation Approach to Improve the} Comprehensive Ability of College Students Effectively

There are many implementation approaches of psychological health education in Colleges and universities, such as discipline infiltration, classroom teaching, extracurricular activities and environmental influence. The infiltration education in the classroom is the dominant mode, while the other methods are the auxiliary roles. Multi-channel and multi-approach to cooperate is the typical characteristics[7]. Through the class-teaching mode for college students to popularize mental health knowledge and teach basic psychological adjustments, which needs a new model of psychological health education to construct a standardized mode, to construct the combination of the compulsory and elective courses, and the curriculum system with the psychological health education as the main part, and supplemented by all kinds of educational activities to construct a new education mode. And discipline penetration is also an effective way of education. On the one hand, the unique role of discipline education in higher education, but also because the subject curriculum itself contains a wide range of psychological 
education resources. In the discipline teaching, the psychological education needs the teachers to design the teaching process according to their physical and mental development characteristics. On the other hand, the majority of educators need to excavate the psychological education factors in the discipline teaching materials, integrate the psychological education and the discipline task, and nurture and train the good psychological quality of the college students[8]. As a supplementary way of class-education, after-school activities not only can make up for the lack of class-education in time, space, content and modes to promote the initiative participation of College students, it also can give full play to the initiative and participation of College students. Extracurricular activities can be carried out through the opening of various psychological quality training courses, psychological lectures, the establishment of psychological clubs, and various psychological knowledge competitions. Through a variety of social activities, to enhance communication and writing of college students, and constantly enhance the social adaptability of college students and the ability to cope with setbacks.

\section{SUMMARY}

In conclusion, this research makes the slaving principle in synergetics, synergetic effect and self-organization function apply in psychological health education of college students collaboratively to break through the limitations of traditional mental health education model effectively. Synergy of counseling model can maximize the effectiveness of mental health education. Synergy of team-work could build high-quality mental health education team. Synergy of educational forces can deconstruct the efficient psychological health education mode. Synergy of implementation approach can improve the comprehensive ability of college students effectively. Meanwhile, model construction of psychological health education in Universities needs the collaboration of social subsystems with guidance mode, work force, education strength, the ways of implementation of collaborative effort.

\section{ACKNOWLEDGEMENT}

This research was financially supported by the Educational Science Research Project of Shaanxi Province(SGH140703)and the Science Research Project of Shaanxi Xueqian Normal University (2016YBKJ066).

\section{REFERENCES}

[1] JL Leishman. Social constructionism, discourse analysis and mental health nursing: a natural synergy[J]. Int J Psychiatr Nurs Res. 2008(5).

[2] JT de Jong. Challenges of Creating Synergy between Global Psychological Health and Cultural Psychiatry[J]. Transcultural Psychiatry. 2014 (7) .

[3] L Qiu, B Chen. A Study on the Curriculum System Construction Psychological Health Education for College Students under the
Guidance of the Curriculum Theory. [J]. Journal of Chongqing university. 2014(9).

[4] SE Baldwin. Synergy: Australian Transcultural Mental Health Network Newsletter[J]. Synergy: Australian Transcultural Mental Health Network Newsletter 2000(4).

[5] M Lee, M Wada, M Suto. Building Synergy in Promoting Mental Health Awareness across University Campus. http://xueshu.baidu.com

[6] DA Regier. Potential DSM-5 and RDoC Synergy for Mental Health Research Treatment and Health Policy Advances. [J]. Psychological Inquiry. 2015(3).

[7] V Patel, M Varghese. NGOs and Mental Health: Search for Synergy [J]. Transcultural Psychiatry.2015(7).

[8] H Higson. Explorations of mental health professionals' views on hope and austerity the synergy of a paradox[J]. Mental Health Practice. 2014.(9). 